\title{
The onset of grapevine berry ripening is characterized by ROS accumulation and lipoxygenase-mediated membrane peroxidation in the skin
}

Stefania Pilati ${ }^{{ }^{*}}$, Daniele Brazzale ${ }^{1}$, Graziano Guella ${ }^{2,3}$, Alberto Milli², Cristina Ruberti ${ }^{4}$, Franco Biasiolii ${ }^{1}$ Michela Zottini ${ }^{4}$ and Claudio Moser ${ }^{1}$

\begin{abstract}
Background: The ripening of fleshy fruits is a complex developmental program characterized by extensive transcriptomic and metabolic remodeling in the pericarp tissues (pulp and skin) making unripe green fruits soft, tasteful and colored. The onset of ripening is regulated by a plethora of endogenous signals tuned to external stimuli. In grapevine and tomato, which are classified as non-climacteric and climacteric species respectively, the accumulation of hydrogen peroxide $\left(\mathrm{H}_{2} \mathrm{O}_{2}\right)$ and extensive modulation of reactive oxygen species (ROS) scavenging enzymes at the onset of ripening has been reported, suggesting that ROS could participate to the regulatory network of fruit development. In order to investigate this hypothesis, a comprehensive biochemical study of the oxidative events occurring at the beginning of ripening in Vitis vinifera cv. Pinot Noir has been undertaken.

Results: ROS-specific staining allowed to visualize not only $\mathrm{H}_{2} \mathrm{O}_{2}$ but also singlet oxygen ( $\left.{ }^{1} \mathrm{O}_{2}\right)$ in berry skin cells just before color change in distinct subcellular locations, i.e. cytosol and plastids. $\mathrm{H}_{2} \mathrm{O}_{2}$ peak in sample skins at véraison was confirmed by in vitro quantification and was supported by the concomitant increase of catalase activity. Membrane peroxidation was also observed by HPLC-MS on galactolipid species at véraison. Mono- and digalactosyl diacylglycerols were found peroxidized on one or both a-linolenic fatty acid chains, with a 13(S) absolute configuration implying the action of a specific enzyme. A lipoxygenase (PnLOXA), expressed at véraison and localizing inside the chloroplasts, was indeed able to catalyze membrane galactolipid peroxidation when overexpressed in tobacco leaves.

Conclusions: The present work demonstrates the controlled, harmless accumulation of specific ROS in distinct cellular compartments, i.e. cytosol and chloroplasts, at a definite developmental stage, the onset of grape berry ripening. These features strongly candidate ROS as cellular signals in fruit ripening and encourage further studies to identify downstream elements of this cascade. This paper also reports the transient galactolipid peroxidation carried out by a véraison-specific chloroplastic lipoxygenase. The function of peroxidized membranes, likely distinct from that of free fatty acids due to their structural role and tight interaction with photosynthesis protein complexes, has to be ascertained.
\end{abstract}

Keywords: Chloroplastic lipoxygenase, Fruit ripening, Galactolipids, Hydrogen peroxide, Oxidative stress, Oxylipin, ROS, Singlet oxygen

\footnotetext{
* Correspondence: stefania.pilati@fmach.it

${ }^{1}$ Research and Innovation Centre, Fondazione Edmund Mach, via E. Mach 1, 38010 San Michele a/Adige, TN, Italy

Full list of author information is available at the end of the article
} 


\section{Background}

Grapevine is an economically important crop, producing fruits that are consumed as fresh berries, pressed juice, dried berries and processed to make wine. Berry quality is determined by parameters measured at harvest, such as sugar content, acidity, skin color, berry size and polyphenol content. These depend on metabolic processes activated in the berry pericarp (skin and pulp) at the onset of ripening, reflecting a deep re-programming of the transcriptome [1-6]. Moreover, skin and pulp develop specialized features during ripening. In particular, skin accumulates anthocyanin to attract animals for seeddispersal, provides a physical barrier against pathogens, avoid berry withering by preventing water loss and protects from solar radiation. This functional specialization is regulated at the transcriptional level [7]. Berry ripening inception is triggered by internal and external stimuli, via complex signal transduction pathways. Internal factors are hormones, such as auxins [8], abscisic acid $[9,10]$, brassinosteroids [11] and ethylene [12,13]; metabolic factors, such sugar accumulation [9] and the increase of turgor pressure [14] and small signaling mediators, such as $\mathrm{Ca}^{2+}[2,15]$. An oxidative burst coinciding with berry color change and the modulation of reactive oxygen species (ROS) scavengers at the gene and protein level have been reported in grapevine, raising the possibility of ROS taking part to the signaling mechanisms occurring at fruit ripening $[3,6,7,16,17]$.

Intracellular ROS can be generated by the incomplete reduction of oxygen or by energy transfer to an oxygen molecule. The first group of ROS are usually by-products of oxidative metabolisms such as respiration, photosynthesis and fatty acid oxidation, respectively occurring in mitochondria, chloroplasts and peroxisomes, and rapidly interconvert into the more stable hydrogen peroxide $\left(\mathrm{H}_{2} \mathrm{O}_{2}\right)$. The latter is represented by singlet oxygen $\left({ }^{1} \mathrm{O}_{2}\right)$ and is produced by energy transfer at the phtosystem II reaction center, inside the chloroplasts [18]. Nonetheless, $\mathrm{H}_{2} \mathrm{O}_{2}$ can also be generated enzymatically by a family of NADPH-oxidases $[19,20]$. Despite their toxicity, at low levels ROS act as signaling molecules $[21,22]$. The specificity and selectivity of ROS signaling depend on the origin, reactivity and spatio-temporal accumulation of each ROS, as highlighted by a meta-analysis of ROS-related microarray experiments [23]. $\mathrm{H}_{2} \mathrm{O}_{2}$ is a signaling factor in plant response to external biotic and abiotic stimuli as well as in developmentally regulated processes (reviewed in [24]). $\mathrm{H}_{2} \mathrm{O}_{2}$ accumulation has been detected in numerous transitional phases of development: in grapevine at the moment of bud break [25], in sunflower during seed dormancy release [26], in tomato and grapevine at fruit ripening [3,27] and in Arabidopsis at floral transition [28]. ${ }^{1} \mathrm{O}_{2}$ is the principal ROS that accumulates in illuminated photosynthetic tissues [29] and can trigger either acclimation or programmed cell death depending on the intracellular abundance [30,31]. A mechanism for plastid-to-nucleus ${ }^{1} \mathrm{O}_{2}$ signaling is based on the generation of small volatiles derived from carotene oxidation which regulate transcription [32].

Among the most abundant molecules prone to ROSinduced damage, there are poly-unsaturated fatty acids (PUFAs), such as linolenic (18:3) and linoleic (18:2) acid. They can be oxidized by different molecules through different mechanisms generating specific regio- and stereoisomers and this feature allows to identify a posteriori the ROS which accumulated. Indeed, lipid peroxidation can be generated either by nucleophilic attack of oxygen radicals, ${ }^{1} \mathrm{O}_{2}$ direct addition or lipoxygenase and $\alpha$-dioxygenase-catalyzed $\mathrm{O}_{2}$ addition [33]. Peroxidized fatty acid chains are rapidly converted into lower-molecular-weight compounds known as oxylipins [34,35], which can act as signaling molecules or be precursors of aromatic volatiles [36]. Jasmonic acid is an oxylipin derived via the lipoxygenase-mediated peroxidation of linolenic acid in the plastids, but also other oxylipins are known to play signaling roles in development [37] and defense [38].

Plant lipoxygenases (LOXs) are 95-100 kDa monomeric proteins with an $\mathrm{N}$-terminal $\beta$-barrel domain $(25-30 \mathrm{kDa})$, known as PLAT, probably involved in membrane or protein interactions, and a C-terminal $\alpha$-helix-rich domain (55-65 kDa) containing the catalytic site, including a nonheme iron coordinated by five amino acid side chains and a water or hydroxide ligand [39]. They are classified according to the positional specificity of linoleic acid oxygenation, i.e. at carbon atom 9 (9-LOX) or 13 (13-LOX), leading to the formation of 9-hydroperoxy and 13-hydroperoxy derivatives (HpODEs and $\mathrm{HpOT} r \mathrm{Es}$ ). All plastidial LOXs are 13-LOXs and usually have a neutral $\mathrm{pH}$ optimum, whereas extra-plastidial LOXs can be either 9-LOXs or 13-LOXs and usually have an alkaline $\mathrm{pH}$ optimum [39].

We carried out a comprehensive analysis of the oxidative burst occurring in Pinot Noir grape berry skin at the onset of ripening to determine the potential signaling roles of ROS in fruit development. We also identified a plastidial LOX, likely responsible for galactolipid peroxidation and oxylipin synthesis, which might represent a novel component of this regulatory network.

\section{Results}

Singlet oxygen and hydrogen peroxide accumulate in Pinot Noir berry skin at the beginning of ripening

The ripening of grapevine cv. Pinot Noir berries was followed during seven weeks starting from pre-véraison stage until mid-ripening (Figure 1A). Berries at pre-véraison (collected at 6 and 7 weeks post flowering (wpf)) were green and hard and were characterized by high content of organic acids and low content of sugars whereas berries 


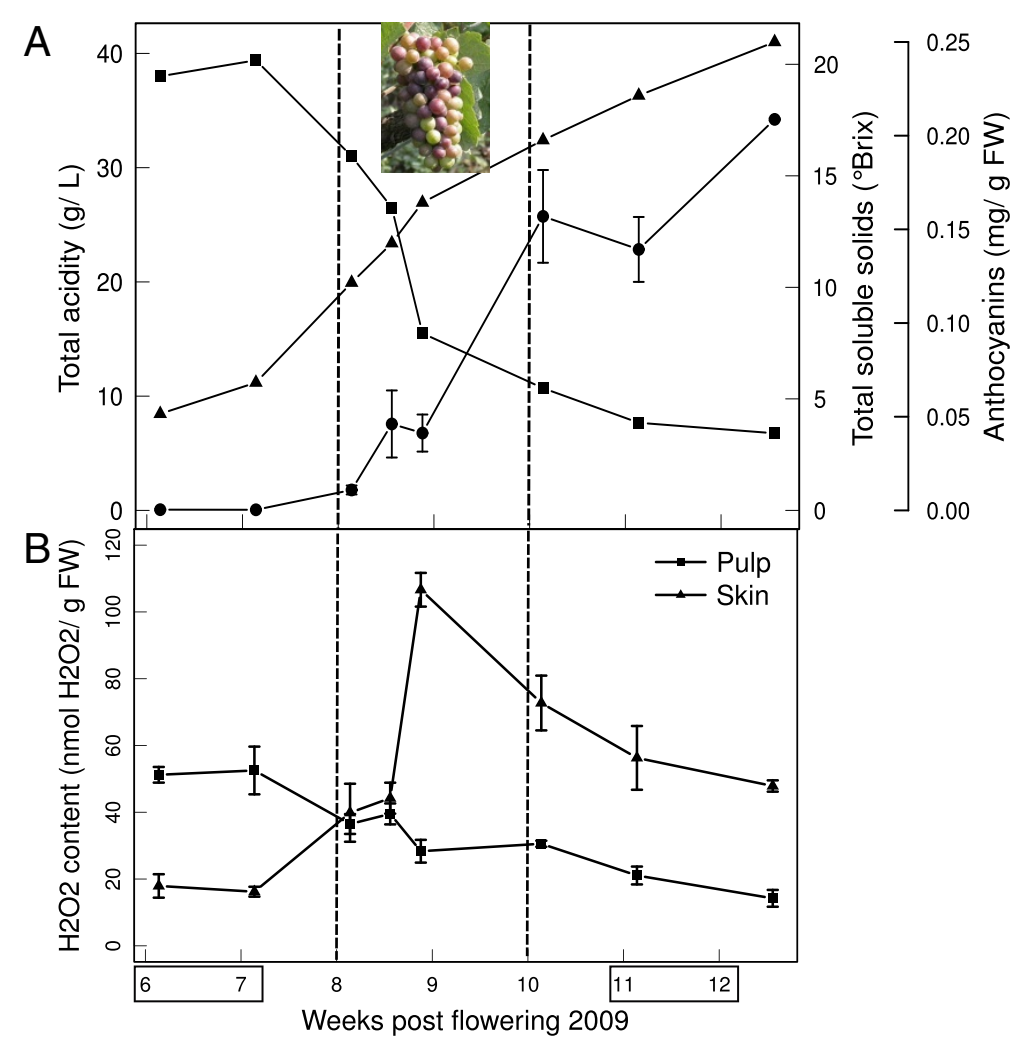

Figure $1 \mathrm{H}_{2} \mathrm{O}_{2}$ content and biochemical changes in Pinot Noir berries during development. A: Mean values of total acids (squares, expressed as grams of tartaric acid per liter) and sugars (triangles, expressed as total soluble solids in ${ }^{\circ}$ Brix) of the must obtained from three clusters, at each time point. Berry skins anthocyanin content (circles) is expressed as grams of pelargonidin-3-glucoside per gram of berry fresh weight. $\mathbf{B}: \mathrm{H}_{2} \mathrm{O}_{2}$ was measured separately in skin and pulp tissues of sampled berries. Data are means of three biological replicates \pm se. The $x$-axis represents time in weeks post flowering (wpf). Véraison is indicated between dashed lines (8-10 wpf). Pre- (6-7 wpf) and post-véraison (11-12 wpf) stages are indicated by boxes. The picture of a cluster at mid-véraison shows the typical asynchrony of berries at this developmental transition.

sampled after 10 wpf were colored, soft, rich in sugars and with a low acidic content. The period between 8 and 10 wpf, named véraison, represents the transition to ripening during which crucial events occur: dramatic opposing changes of organic acids and sugars contents in the pulp, softening of the fruit and coloring of the skin. These changes do not take place in a synchronous way among berries of the same cluster, as shown in the picture of Figure 1A. As clusters were sampled by date and berries randomly pooled for must and pigment analyses, the obtained profiles, reported in Figure 1A, were smooth and diluted in time. Conversely, when sampling is based on physico-chemical characteristics of the berries, as for instance in [7], the differences between developmental stages are more sharp and larger.

$\mathrm{H}_{2} \mathrm{O}_{2}$ levels were measured separately in the skin and pulp of Pinot Noir berry samples (Figure 1B). While in the pulp a gradual decrease of $\mathrm{H}_{2} \mathrm{O}_{2}$ was observed, in the skin there was a clear accumulation of $\mathrm{H}_{2} \mathrm{O}_{2}$ at the beginning of ripening, with a maximum in samples collected at 9 wpf. This result leads to the conclusion that the transient peak in $\mathrm{H}_{2} \mathrm{O}_{2}$ content previously observed in whole berries at véraison [3] was actually contributed predominantly by the skin. A similar profile was observed in Pinot Noir during season 2008 (Additional file 1A). Taken in consideration the fact that samples collected by date are quite heterogeneous and that $\mathrm{H}_{2} \mathrm{O}_{2}$ accumulation is usually a fast event, its increase between 8 and 10 wpf likely corresponds to the proportion of berries undergoing the transition to ripening rather than to $\mathrm{H}_{2} \mathrm{O}_{2}$ increase within a single berry. As our interest is focused on cell signals, we did not further investigate the decreasing profile of $\mathrm{H}_{2} \mathrm{O}_{2}$ in the pulp, instead we characterized the events occurring in the skin.

\section{Imaging of ${ }^{1} \mathrm{O}_{2}$ and $\mathrm{H}_{2} \mathrm{O}_{2}$ at the onset of ripening}

Single berries at the three developmental stages around the onset of ripening (green hard, green soft and pale red) were collected at $9 \mathrm{wpf}$ in 2011 and sliced with a microtome to be used for ROS detection. ROS imaging was carried out by staining with three fluorescent dyes each specific for three type of ROS: dichlorofluorescein diacetate (DCFDA), which is sensitive to most ROS, hydroxyphenyl fluorescein (HPF), which is specific for 
strong oxidants such as the hydroxyl radical and peroxynitrite anion, and singlet oxygen sensor green (SOSG), which is specific for ${ }^{1} \mathrm{O}_{2}$. Confocal images of sections stained with DCFDA and SOSG revealed the presence of ROS at the green soft and pale red stages and in the outer cell layers, i.e. those composing the skin (Figure 2, upper row). HPF did not yield a signal (not shown), suggesting that the ROS detected with DCFDA were weak oxidants, such as $\mathrm{H}_{2} \mathrm{O}_{2}$. The merge of the pictures obtained recording DCFDA/SOSG and chlorophylls fluorescence signals superimposed to the bright field showed that the localization of $\mathrm{H}_{2} \mathrm{O}_{2}$ and ${ }^{1} \mathrm{O}_{2}$ was different at the subcellular level: $\mathrm{H}_{2} \mathrm{O}_{2}$ was detected in the cytosol whereas ${ }^{1} \mathrm{O}_{2}$ exclusively in the plastids (Figure 2, bottom row).

Catalase activity is strongly enhanced in the berry skin during ripening

Catalase activity was investigated due to its relevance to $\mathrm{H}_{2} \mathrm{O}_{2}$ scavenging. It was initially visualized in total protein berry skin extracts by zymography as a strong single band in the samples collected at 10-12 wpf, indicating the activation of one specific isoform (Figure 3A). Catalase activity was then quantified in vitro by spectrophotometry (to measure $\mathrm{H}_{2} \mathrm{O}_{2}$ consumption) and by proton transfer reaction-mass spectrometry (to measure in-line $\mathrm{O}_{2}$ production), to unequivocally distinguish catalase from other scavenger activities (Figure 3B). Both assays confirmed the strong increase at $10 \mathrm{wpf}$, suggesting that catalase contributes to $\mathrm{H}_{2} \mathrm{O}_{2}$ scavenging after véraison. According to our results, the low level of $\mathrm{H}_{2} \mathrm{O}_{2}$ at prevéraison cannot be attributed to a catalase scavenging activity and the following increase at véraison must thus be linked to an augmented ROS production, as commented in the discussion.

\section{Galactolipid peroxidation occurs at the onset of ripening} Membrane lipids were analyzed with the aim to detect characteristic modifications caused by ROS accumulation. Crude lipid extracts were analyzed without preprocessing (e.g. fatty acid hydrolysis or derivatization) in order to study cell membrane lipid composition. Initially, the presence of peroxidized galactolipids at véraison was detected by MALDI-TOF mass spectrometry on extracts

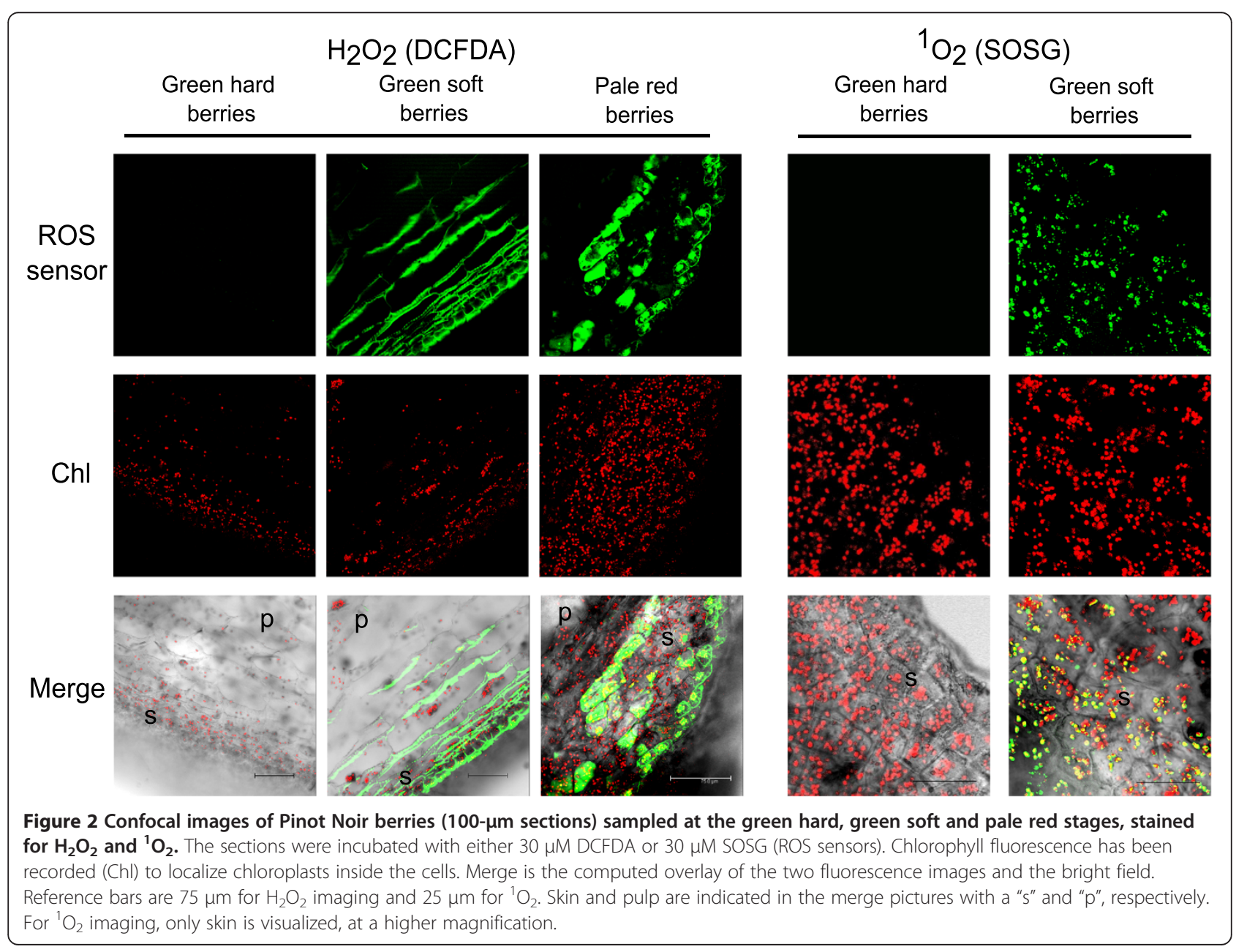




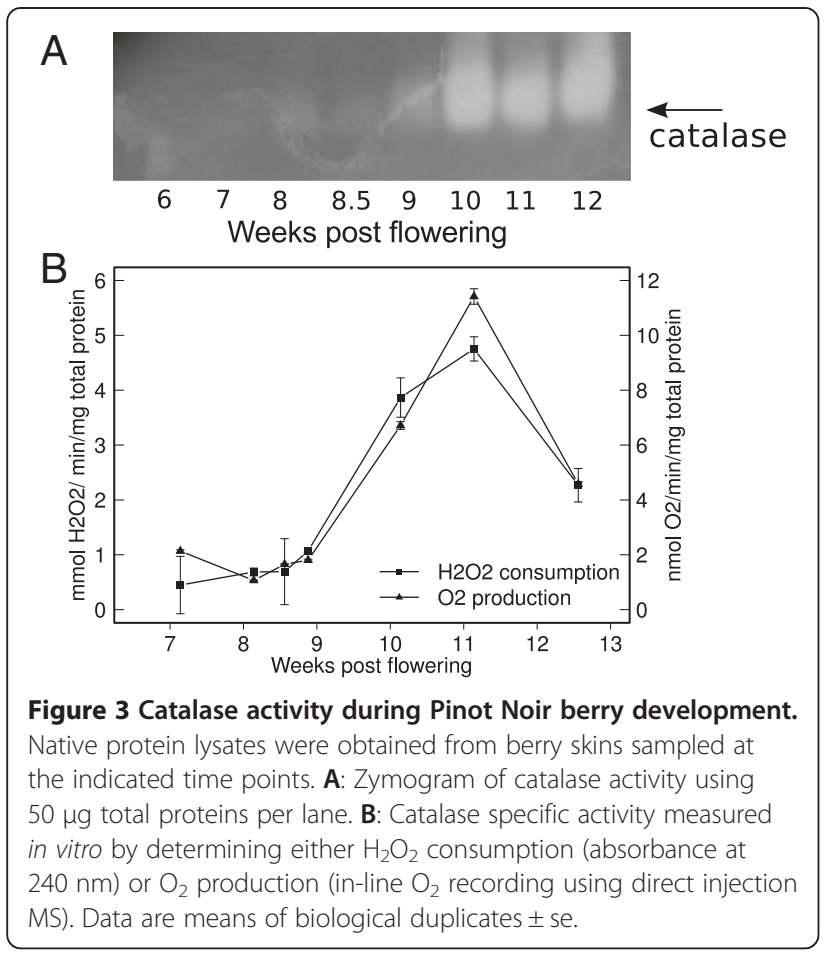

of berries collected during 2008 (Additional file 1B). Then, lipid extracts prepared from berries collected during 2009 season were analyzed by chromatographic separation coupled to mass spectrometry identification, as outlined in Figure 4. Three peaks absorbing at 234 $\mathrm{nm}$ were identified as oxidized lipids, as this wavelength is specific of the conjugated diene bonds formed during PUFAs oxidation. They were identified as the oxidized forms of monogalactosyl diacylglycerol and digalactosyl diacylglycerol carrying two $\alpha$-linolenic fatty acid chains (MGDG 36:6 and DGDG 36:6). MGDG 36:6 and DGDG 36:6 were indeed the most abundant galactolipid species. Their structures were determined by full-scan electrospray ionization (ESI) in positive-ion mode (Figure 4, MS peaks 1 and 2) where they appeared as $[\mathrm{M}+\mathrm{Na}]^{+}$ and $[\mathrm{M}+\mathrm{K}]^{+}$ion adducts and showed the same ion fragment at $m / z 595$ reflecting the loss of the corresponding sugar moiety. ESI-MS/MS on the $[\mathrm{M}+\mathrm{Na}]^{+}$ion adducts revealed strong fragment signals at $m / z 519$ (MGDG) and 681 (DGDG), reflecting the loss of linolenic acid at the primary position on the glycerol backbone, thus suggesting the presence of two identical 18:3 acyl chains in both the membrane lipids [40]. The analysis of purified samples containing MGDG and DGDG by ${ }^{1} \mathrm{H}-\mathrm{NMR}$ spectroscopy confirmed the presence of characteristic signals representing monogalactose $\left(\delta_{\mathrm{H}} 4.23 \mathrm{~d}, 7.3 \mathrm{~Hz}\right.$ for the $\alpha$-acetal proton of $\beta$-galactose $)$ and digalactose $\left(\delta_{\mathrm{H}} 4.87 \mathrm{~d}, 3.7 \mathrm{~Hz}\right.$ for the $\beta$-acetal proton of the $\alpha$-galactose moiety in the digalactose structure) and also confirmed the presence of the $9 \mathrm{Z}, 12 \mathrm{Z}, 15 \mathrm{Z}$ octadecatrienoic ( $\alpha$-linolenic) acyl group for both the unsaturated chains.

Comprehensive HPLC-MS analysis of the peaks with lower retention times indicated the presence of more polar lipids in the extracts, strongly absorbing at 234 $\mathrm{nm}$. These species gave ESI(+) mass spectra with ion adducts and fragment ions $16 \mathrm{Da}$ heavier than the corresponding native galactolipids, indicating the presence of an additional hydroxyl group on one of the acyl chains (Figure 4, peaks 3 and 4). In the ESI(+) mass spectrum of peak $3\left(\lambda_{\max } 234 \mathrm{~nm}\right)$, the ions at $m / z 813$ and 611 therefore represent the mono-oxidized forms of MGDG 18:3/18:3 (peak $1, m / z 797$ and 595), whereas in the ESI(+) mass spectrum of peak $4\left(\lambda_{\max } 234 \mathrm{~nm}\right)$, the ions at $\mathrm{m} / z 975$ and 611 represent the mono-oxidized forms of DGDG 18:3/18:3 (peak 2, $m / z 959$ and 595). At lower retention times, we also detected di-oxidized forms of MGDG 18:3/18:3 (peak 5, $[\mathrm{M}+\mathrm{Na}]^{+}$at $\mathrm{m} / z$ 829, $\lambda_{\max } 234 \mathrm{~nm}$ ) and DGDG 18:3/18:3 (peak 6, not showed in the chromatogram of Figure $4,[\mathrm{M}+\mathrm{Na}]^{+}$at $m / z$ 991, $\left.\lambda_{\max } 234 \mathrm{~nm}\right)$. ESI-MS/MS of the mono-oxidized MGDG 18:3/18:3 $(\mathrm{m} / z$ 813) revealed two fragment ions at $\mathrm{m} / z 535$ and 519 due to the loss of $\alpha$-linolenic acid and oxidized $\alpha$-linolenic acid, respectively. Because this neutral loss should occur more frequently at the primary glycerol position [40], the finding of equally populated fragment ions strongly indicates that the two acyl chains have a similar oxidation propensity. ESI-MS/MS of the di-oxidized MGDG 18:3/18:3 ( $\mathrm{m} / \mathrm{z}$ 829) revealed only one fragmentation at $\mathrm{m} / \mathrm{z} 535$ reflecting the loss of mono-oxidized $\alpha$-linolenic acid, thus ruling out the presence of di-oxidized acyl chains.

The regio and stereo-specificity of the hydroxyl group on the $\alpha$-linolenic chain, obtained by alkaline hydrolysis of the oxidized MGDG 36:6, was then studied (Figure 5). Because fragmentation, besides common loss of neutral molecules $\left(\mathrm{H}_{2} \mathrm{O}\right.$ and $\left.\mathrm{CO}_{2}\right)$, mainly occurs at the two C-C bonds adjacent to the carbon atom bearing the hydroxyl group, the intense daughter ions at m/z 195 and 223 obtained by collision-induced dissociation of the parent ion at $\mathrm{m} / \mathrm{z} 293$ (mono-oxidized $\alpha$-linolenic carboxylate) unambiguously established the regiochemical position of the $-\mathrm{OH}$ function at the position 13 of the linolenic acyl chain [33]. Finally, we used circular dichroism (CD) spectroscopy to determine the absolute configuration of the $\mathrm{C}(13)$-oxidized galactolipids. We found that the $\mathrm{CD}$ spectrum of the compound obtained after alkaline hydrolysis of the oxidized MGDG 36:6 from berry skins was identical to the CD spectrum of commercially available (9Z,11E,15Z)-13-(S)-hydroxyoctadecatrienoic acid (13HOTrE), thus indicating a 13-S absolute stereochemistry (Figure 5).

Quantification of the oxidized MGDG and DGDG species in Pinot Noir berry skin along development showed 


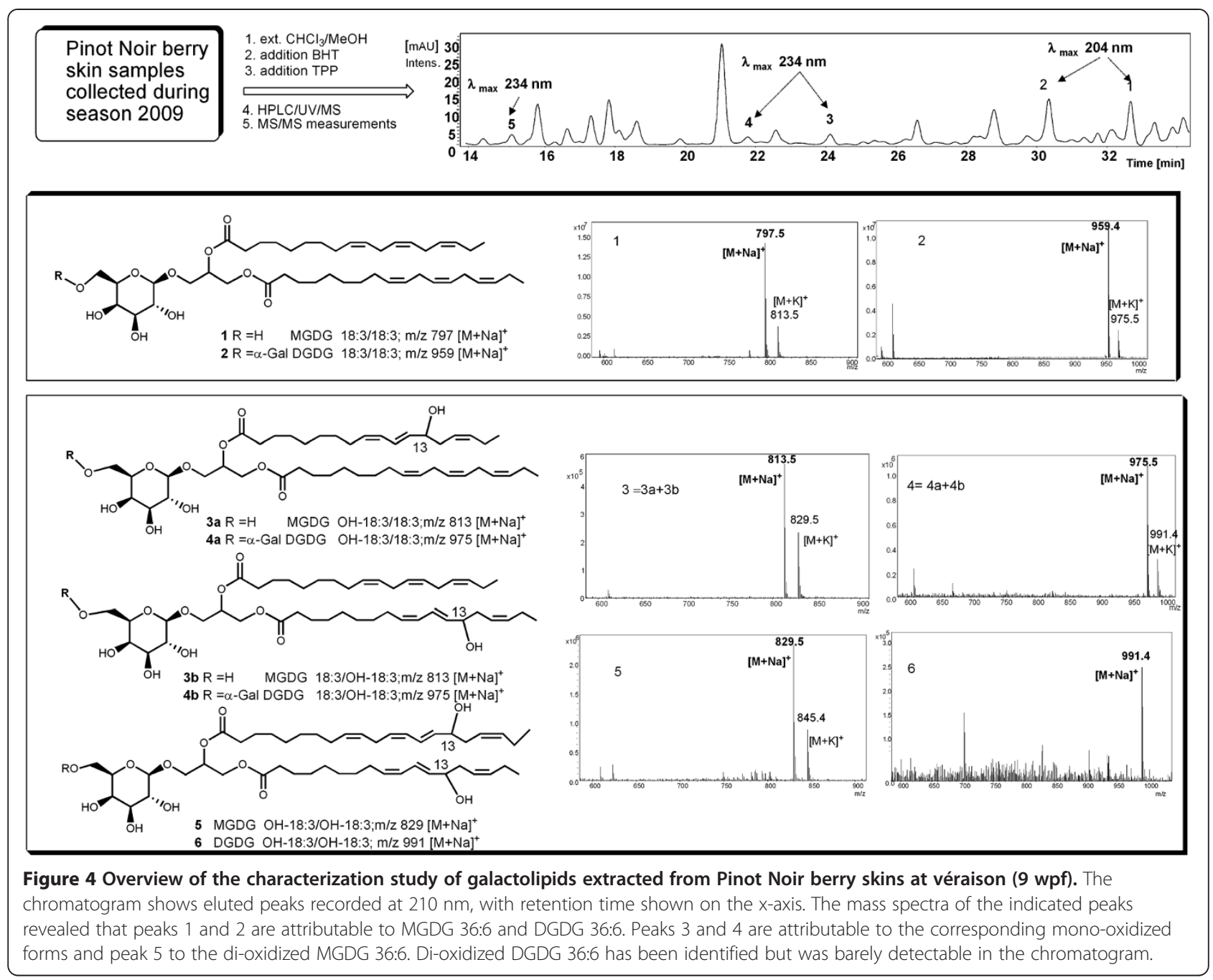

a transient peak of accumulation at $9 \mathrm{wpf}$, mirroring the accumulation of $\mathrm{H}_{2} \mathrm{O}_{2}$ (Figure 6). By statistically comparing the relative amount of oxidized lipids present in the samples representing pre-véraison (6-7 wpf), véraison (8.5-9 wpf) and ripening (11-12 wpf) stages, it was evident that galactolipids oxidation state at véraison was significantly different from the other two stages considered. As the MGDG:DGDG ratio ranged from 1 to 0.8 , the fact that MGDG reached a higher level of peroxidation $(6 \%$ and nearly $2 \%$ for the mono- and di-oxidized forms vs. $3.5 \%$ of mono-oxidized DGDG) suggests that MGDG is oxidized preferentially. Moreover, even if di-oxidized MGDG showed the highest increase in terms of fold change, they accumulated to a lower extent than the mono-oxidized ones, suggesting they are less stable.

\section{A plastidial 13-lipoxygenase catalyzes galactolipid peroxidation at the onset of ripening}

Western blot analysis of total protein extracts obtained from berry skin samples collected during 2009 was performed using a commercial antibody raised against the Arabidopsis plastidial LOX2 to characterize the presence of LOX activity in concurrence with galactolipid peroxidation. A single $95-100 \mathrm{kDa}$ band was observed in the samples harvested from 8.5 to $11 \mathrm{wpf}$ (Figure 7A). We wanted to identify the proteins contained in that band by MS analysis, but their amount was below the instrument sensitivity. In the attempt to enrich the sample in chloroplastic LOXs, plastids were isolated from fresh berry skin collected in 2011 at the green soft/pink stage (9 wpf) using a Percoll gradient.Chloroplasts were lysed and their content partitioned into stromal and thylakoid-enriched fractions. All the obtained fractions were analyzed for LOX expression by western blot (Figure 7B). Pinot Noir LOX was found predominantly in the thylakoid-enriched fraction, which was then used for tryptic digestion and MS analyses (Additional file 2). nanoLC/MS sequencing identified one peptide unambiguously matching Vv06s0004g01510, a 13-LOX differing at only five out of 901 residues from the recently described Sauvignon Blanc LOXA [41]. This 


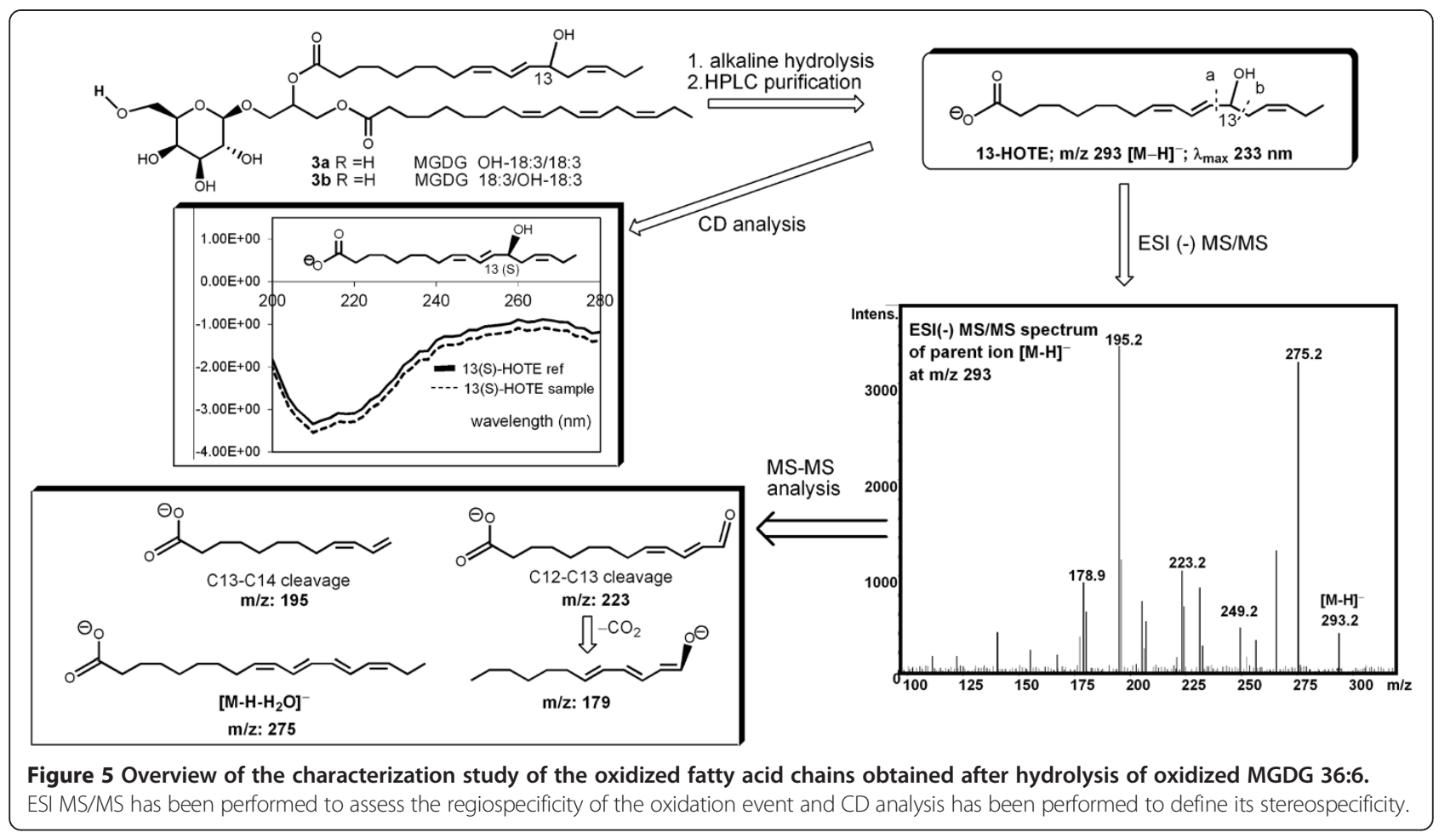

result was confirmed by comparative MALDI-TOF/MS analysis performed on this fraction and on recombinant Vv06s0004g01510 protein. We therefore named the protein PnLOXA.

PnLOXA gene expression was analyzed by RT-PCR in a panel of Pinot Noir tissues and in developing berry

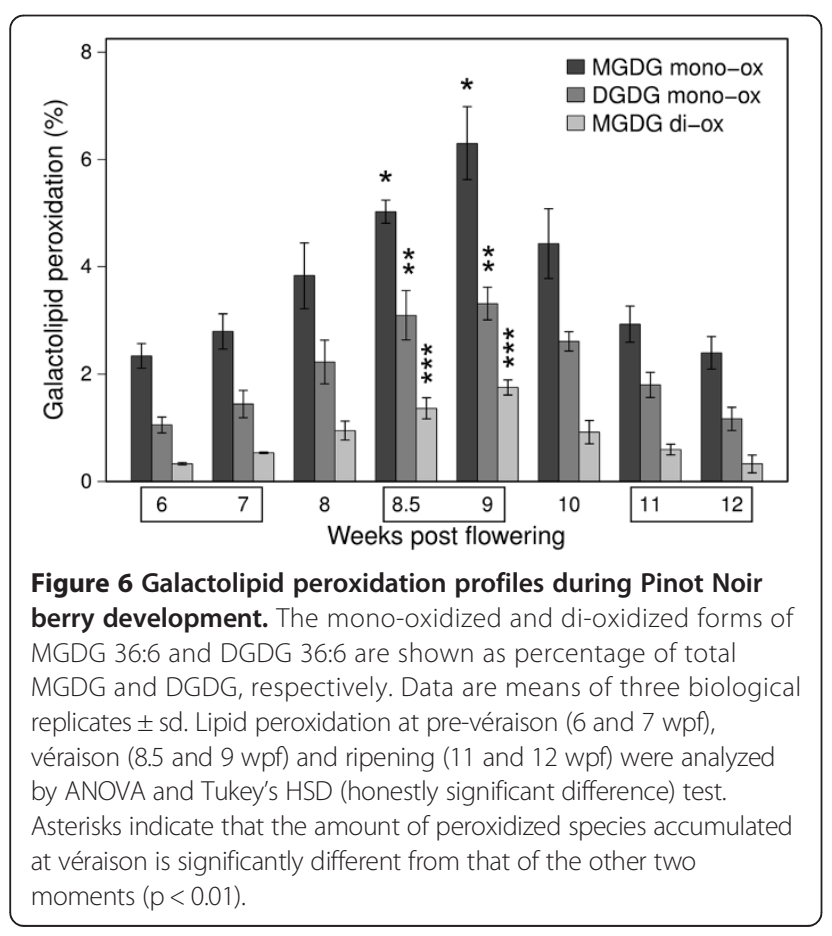

skin (season 2009). We observed a 20 -fold increase in its expression at the onset of ripening (Figure 8) matching precisely with the peaks of protein abundance detected by western analysis (Figure 7A) and of galactolipid peroxidation (Figure 6). Statistical comparison among the three berry development stages defined above highlighted that PnLOXA expression at véraison was significantly different from pre-véraison and ripening stages. PnLOXA expression was not restricted to the berry. Indeed, the gene was expressed in all the photosynthetic tissues we analyzed, particularly in plant structures undergoing developmental changes (such as bud and inflorescence). These results agree with in silico analysis of $L O X$ gene expression in the grapevine atlas ([42], Additional file $3 \mathrm{~A}$ ): the only tissues where PnLOXA is not expressed are woody stem, root and senescent leaf while in winter bud it is minimally expressed. Conversely, it is highly expressed in inflorescence, flower, bud, tendril and berry at véraison. The atlas data show that five $L O X$ genes are modulated during berry development: two 9-LOX (Vv05s0020g03170 and Vv14s0128g00790) and three 13-LOX genes (PnLOXA, Vv09s0002g01080 and $V v 01 s 0010 g 02750)$. However, only PnLOXA shows an induction at véraison (Additional file $3 \mathrm{~B}$ ). Primary structure analysis of PnLOXA indicated the presence of a plastid targeting peptide (residues 1-47), a PLAT domain which might be involved in protein-protein or protein-lipid interactions (72-204), and a C-terminal catalytic domain that coordinates $\mathrm{Fe}^{3+}$ (207-901). We created two fusion 


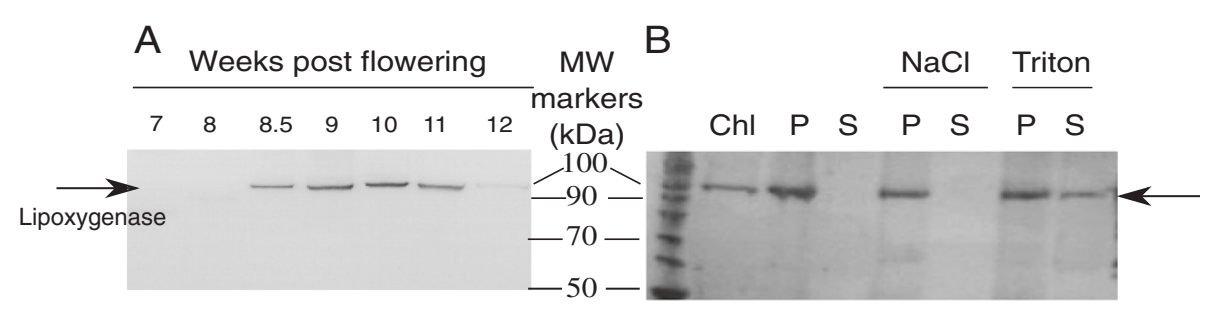

Figure 7 Western blot analysis of lipoxygenase expression in Pinot Noir berry skin extracts. A: Analysis of plastid lipoxygenases expression during berry development using a commercial antibody against Arabidopsis LOX2 and $10 \mu \mathrm{g}$ of total protein extracts per lane. B: Analysis of plastid lipoxygenase expression in chloroplast-enriched samples obtained from fresh berry skins collected at 9 wpf. Total chloroplast protein extract (Chl) was fractionated into membrane (P) and soluble (S) fractions by centrifugation. Membrane pellets were treated with $1 \mathrm{M} \mathrm{NaCl}$ or $0.05 \%$ Triton X-100, incubated for 10 min on ice and centrifuged again to separate the membrane (P) and the soluble (S) fractions. Pellets were resuspended in a volume identical to the corresponding soluble fractions and loaded in equal amounts for separation by SDS-PAGE and detection by western blot. MW markers: molecular weight markers $(\mathrm{kDa})$.

constructs with yellow fluorescent protein (YFP): one containing only the transit peptide to study PnLOXA intracellular localization and the other containing also the PLAT domain to gain insights into its function. Transient expression of the first construct in grapevine and tobacco leaves followed by confocal imaging showed that YFP was efficiently translocated into the chloroplasts (Figure 9 and Additional file 4, left column). The presence of the PLAT domain is responsible of a non-uniform distribution of YFP fluorescence inside the plastid, consistent with that of a thylakoid-associated protein (Figure 9 and Additional file 4, right column). Similar results, showing a spot-like localization inside the chloroplast, were reported for potato and tomato lox $[43,44]$. The in vivo localization supports the previous chloroplast fractionation experiment (Figure 7B) and suggests that the PLAT domain is involved in protein localization at the thylakoid.

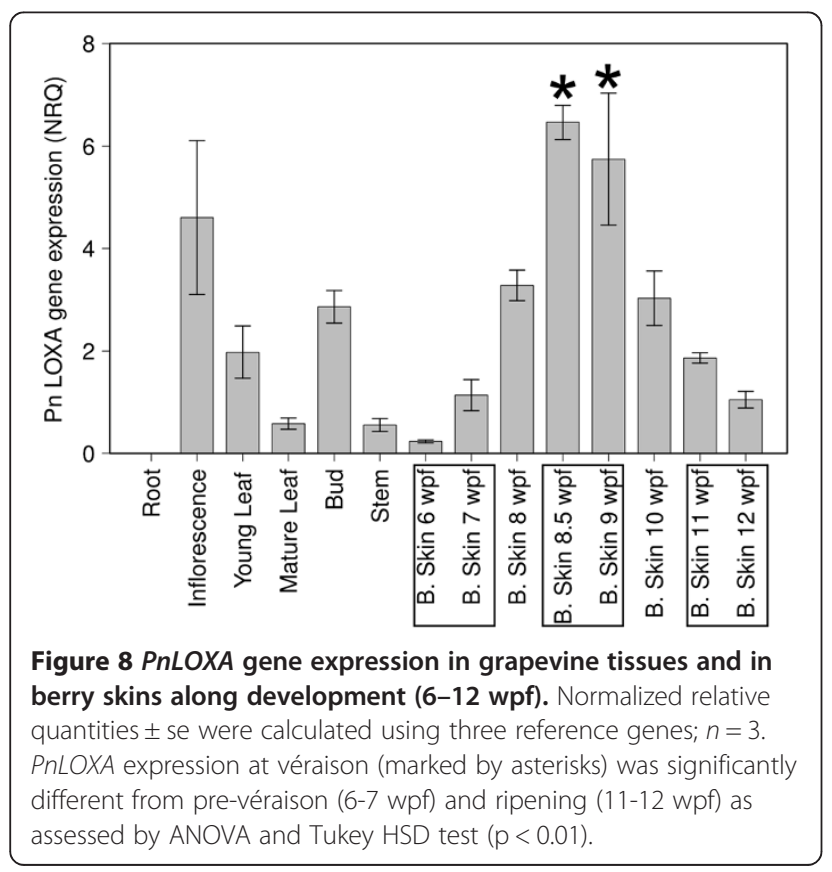

Finally, we analyzed PnLOXA enzymatic activity to confirm its ability to peroxidize free fatty acid chains and also membrane galactolipids. The mature protein was firstly expressed in E. coli, purified by ion-chelating affinity chromatography and tested in vitro. PnLOXA catalyzed the regiospecific peroxidation of $\alpha$-linolenic acid to produce exclusively 13-HOTrE (ESI-MS/MS analysis). To test the ability of the enzyme to catalyze the

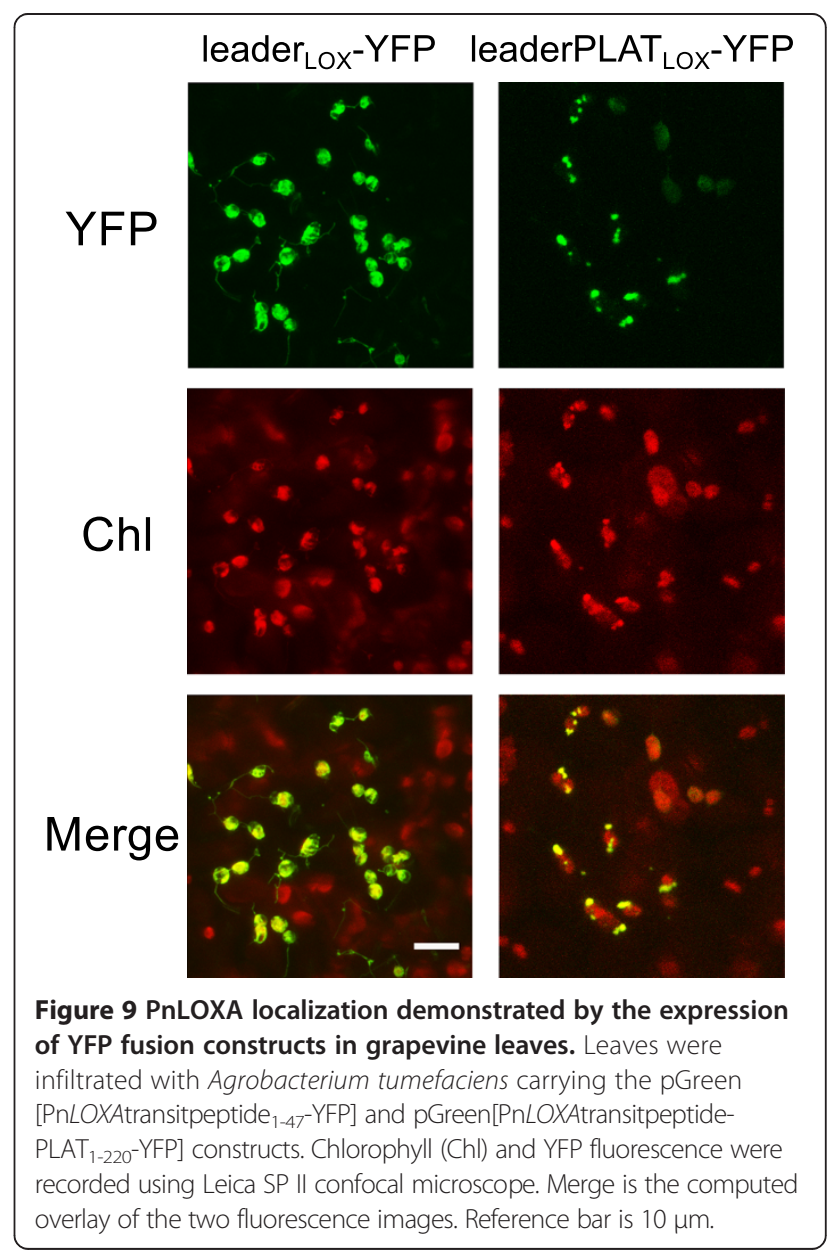


peroxidation of galactolipids, we incubated PnLOXA with the most pure galactolipid fraction isolated from grape berry skins, which was that enriched in DGDG. PnLOXA efficiently catalyzed the 13-peroxidation of DGDG 36:6, producing both mono-oxidized (3.6\%) and di-oxidized products $(5.6 \%)$. Table 1 shows the degree of peroxidation within each DGDG species: the prevalence of di-oxidized forms indicates that PnLOXA acts on both galactolipid chains without significant discrimination. We also studied membrane lipid peroxidation in vivo by transiently overexpressing $P n L O X A$ in tobacco leaf cells. We agro-infiltrated leaves with either the PnLOXA construct or the empty vector and collected leaf transformed spots during the following days for protein expression analysis. Overexpression of PnLOXA, monitored by western blot, reached a maximum at 7 days after transformation (not shown). The experiment was then repeated in biological triplicates collecting samples 7 days after infiltration and lipid extracts were analyzed by HPLC-MS. The amount of oxidized species in the control samples was nearly detectable, whereas the presence of the grapevine enzyme caused a statistically significant increase of galactolipid peroxidation (Figure 10). The amount of peroxidized galactolipids was normalized to the amount of PnLOXA protein actually present in each replicate (see Additional file 5) and used to calculate the average peroxidation value. As in grapevine berry skin, also in tobacco leaves MGDG seem preferentially oxidized; however in the latter, di-oxidized galactolipids accumulate more than mono-oxidized species (as observed in vitro, Table 1).

\section{Discussion}

The transition from mature green to ripening berries is a crucial developmental phase in grapevine, as well as in many fleshy fruits, because it involves broad metabolic reprogramming and definitive specialization. Internal signals (developmental, hormonal and metabolic) refined by external cues trigger a set of integrated regulatory cascades, possibly including a burst of oxidative stress, at the transition to the ripening phase $[3,6,7,16,17]$. This study definitely confirms the transient accumulation of $\mathrm{H}_{2} \mathrm{O}_{2}$ in the cytosol of berry skin cells at the beginning of ripening and shows the concomitant accumulation of
${ }^{1} \mathrm{O}_{2}$ inside chloroplasts (Figure 2), where also enzymatic peroxidation of membrane galactolipids occurs.

Although it is difficult to measure $\mathrm{H}_{2} \mathrm{O}_{2}$ in plant tissues accurately [45], it clearly accumulates in berry skin at softening and color change (Figures 1, 2 and Additional file 1A). Basal levels are probably restored by the activity of a catalase isoform which is specifically expressed and active since $10 \mathrm{wpf}$ (Figure 3). This catalase isoform resembles Arabidopsis CAT3, which is stress- and substrate-inducible and is expressed at bolting time, when a peak of $\mathrm{H}_{2} \mathrm{O}_{2}$ occurs in the leaves and senescence is triggered [46]. We have no evidence to attribute the accumulation of $\mathrm{H}_{2} \mathrm{O}_{2}$ to a down-regulation of scavenger activities, at least of catalase, rather we might speculate about an increase in ROS production at ripening onset. Potential sources could be chloroplasts, which are undergoing a transition to non-photosynthetic organelles, or mitochondria, which transiently shift to an aerobic fermentative metabolism [47].

$\mathrm{H}_{2} \mathrm{O}_{2}$ accumulation and catalase activity are reported also at bud-break in grapevine [48-51], where the role of $\mathrm{H}_{2} \mathrm{O}_{2}$ as a signal molecule in the release of buds endodormancy has been proposed.

In plants, ${ }^{1} \mathrm{O}_{2}$ is usually generated at photosystem II by energy transfer from excited triplet chlorophylls to triplet oxygen $\left(\mathrm{O}_{2}\right)$ under photo-oxidative conditions [52]. At the onset of ripening, a developmentally regulated switch off of photosynthesis occurs and ${ }^{1} \mathrm{O}_{2}$ is likely to be generated. Quite unexpectedly, we do not detect significant oxidative damage on thylakoid membrane lipids attributable to ${ }^{1} \mathrm{O}_{2}$, rather the lipoxygenase-mediated accumulation of 13-peroxy galactolipids (Figures 4 and 5). At 9 wpf, $6 \%$ of the MGDG and $3.5 \%$ of the DGDG are oxidized on one chain and nearly $2 \%$ of the MGDG are oxidized on both chains (Figure 6). A grapevine plastidial 13-lipoxygenase (PnLOXA) probably responsible for the transient galactolipid peroxidation in Pinot Noir grapes has been identified. It differs at only five out of 901 residues from the Sauvignon Blanc orthologue [41]. The véraison-specific expression profile of this LOX isoform (Figures 7 and 8) was already highlighted in a proteomic study which proposed it as a biomarker of grapevine ripening [53]. According to the Vitis atlas [42] other two 13-LOX genes are

Table 1 In vitro galactolipids peroxidation after incubation with purified recombinant PnLOXA (10 minutes at $\left.25^{\circ} \mathrm{C}\right)$, expressed as relative percentage over total DGDG within each class

\begin{tabular}{lllll}
\hline & Chain composition & Mono-oxidized (\%) & Di-oxidized (\%) & Relative abundance in the extract (\%) \\
\hline DGDG 36:6 & $18: 3 / 18: 3$ & 1.6 & 9.8 & 51.3 \\
DGDG 34:3 & $18: 3 / 16: 0$ & 9.3 & 0 & 14.2 \\
DGDG 36:3 & $18: 3 / 18: 0$ & 9.3 & 0 & 13.9 \\
DGDG 36:4 & $75 \% 18: 3 / 18: 1$ 25\% 18:2/18:2 & 8.5 & 1.2 & 7.6 \\
DGDG 36:5 & $18: 2 / 18: 3$ & 0 & 7.6 & 6.4 \\
\hline
\end{tabular}




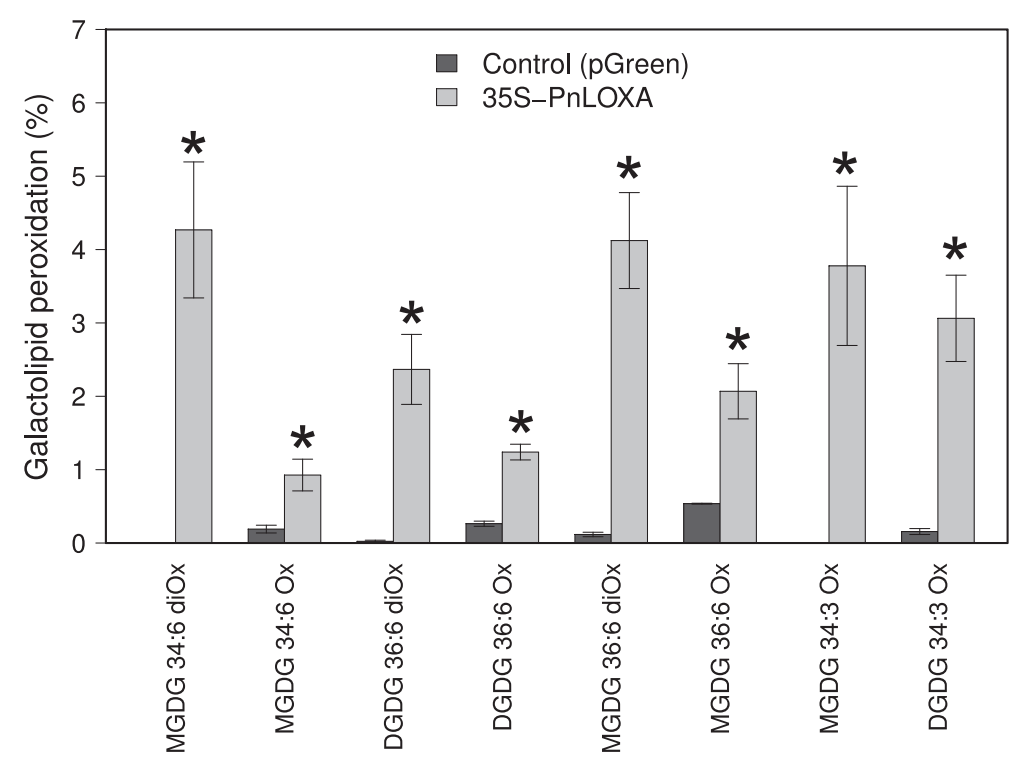

Figure 10 Galactolipid analysis of tobacco leaves transiently expressing PnLOXA. Leaves transformed either with the PnLOXA or the empty vector ( $p$ Green) as control were collected 7 days after Agrobacterium inoculation. Galactolipid peroxidation is reported as a percentage of mono- and di-oxidized species within each class, normalized on the amount of PnLOXA protein. Data are means of three replicates \pm sd. ANOVA and Tukey HSD test were performed to compare control and PnLOXA over-expressing samples. Asterisks indicate significant differences from control at $p<-0.05$.

expressed in the berry, but with a descending profile from fruit set to full ripening. Moreover, one of these, $L O X O$, is induced by abiotic and biotic stresses, such as wounding and Botrytis infection [41] and is regulated by VvWRKY1 in response to downy mildew [54]. An important feature of PnLOXA is the ability to peroxidize membrane galactolipids both in vitro and in vivo (Table 1 and Figure 10) and not only free fatty acid chains, as it is usually assumed. Moreover, PnLOXA causes the preferential accumulation of di-oxidized forms of MGDG and DGDG. We can thus conclude that in the fruit skin the di-oxidized MGDG do not accumulate due to a very fast scavenging or conversion. Similar conclusions were reported for Arabidopsis chloroplastic lipoxygenase LOX2 [55]. The study of lox2 mutant suggested that LOX2 could directly oxidize membrane galactolipids and that di-oxidized forms were strictly related to its presence, whereas mono-oxidized forms accumulation occurred also in a lox2 background. Finally, the preferential accumulation of oxidized MGDG was observed: we speculate that this phenomenon could be related to a PLAT-mediated specific localization of PnLOXA at the thylakoid (Figure 9), rather than to substrate discrimination. In fact, MGDG and DGDG have distinct structural properties and distribution in the membrane and there are proteins known to interact preferentially with MGDG, such as violaxanthin de-epoxidase and cytochrome b6f $[56,57]$.

The biological function of enzymatically generated membrane peroxy-lipids in the chloroplast at the onset of ripening is not clear yet. Usually peroxidation occurs on free fatty acid chains and generates, through catalyzed or spontaneous reactions, compounds called oxylipins, among which the hormone jasmonic acid [34]. The signaling function of oxylipins is well established, as many studies have demonstrated their influence on physiological processes such as root development and plant defense in Arabidopsis [37] and light acclimation in Chlamydomonas [58]. Besides, some oxylipins are volatile aromatic compounds, such as C6 volatile aldehydes, alcohols and esters, which confers the characteristic flavors to fruits including grapes and wine [36]. In tomato, a chloroplastic LOX expressed in the fruit at the moment of color change, named TomLOXC (U37839), has been related to the aroma flavor of ripe fruits [44,59-61]. A phylogenetic analysis based on protein sequence similarity shows that TomLOXC and PnLOXA belong to the same group of chloroplastic 13-LOX (Additional file 6), suggesting they could have conserved functions in the two fruits. The observation that their expression pattern is centered at véraison rather than at ripening, when the aroma are accumulated, and that TomLOXC is directly activated by the MADS box transcription factor RIN, which is a major regulator of the onset of ripening in tomato [62], strongly support the hypothesis of these LOXs participation to fruit development signaling. Moreover, the peculiarity of PnLOXA of peroxidizing membrane lipids instead of free fatty acid chains allows to speculate on at least other two possible functions of peroxy-lipids. On the one hand, membrane peroxidation could undergo fragmentation and generate a particular class of oxylipins, 
namely phytoprostanes with signaling function [35,63], while on the other hand it could regulate membrane proteins activity by reversible oxidation of active-site cysteines, as reported for a human protein tyrosine phosphatase [64].

\section{Conclusion}

This work sheds light on the oxidative species transiently accumulating in the skin of grapevine berries at the onset of ripening. Skin cells are continuously exposed to solar radiation, even during the programmed dismantling of the photosynthetic apparatus at the onset of ripening. In this transitional phase, ROS could exceed skin cells scavenging capacity, accumulate and affect the transcription of nuclear genes involved in photo-protection and ROSscavenging. Besides, the enzymatic peroxidation of thylacoidal membranes may represent the first step in oxylipin synthesis or a mechanism to regulate membrane proteins through redox control.

\section{Methods}

\section{Plant material and biochemical analysis}

Three clusters of grape berries (Vitis vinifera cv. Pinot Noir ENTAV115) were collected during 2008 and 2009 at FEM study site between 9 and 10 am at eight time-points between 6 and 13 weeks post flowering (wpf, flowering is intended as $50 \%$ of open flowers in the vineyard). Half of each cluster was immediately frozen in liquid nitrogen and the other half was pressed for must analysis by means of Fourier transform infrared spectroscopy (FTIR) using the instrument WineScanTM Type 77310 (Foss Electric, Denmark). Frozen berries were peeled with a scalpel, separating the most external cell layers (exocarp, skin) from the rest (mesocarp and endocarp, pulp). Skin and pulp, were ground separately to obtain a fine powder. The anthocyanin concentration in the skin was measured after methanol extraction ( $1 \mathrm{~g}$ berry skin powder in $10 \mathrm{ml}$ methanol) according to the double $\mathrm{pH}$ differential method [65]. $\mathrm{H}_{2} \mathrm{O}_{2}$ was measured using the Amplex UltraRed (Molecular Probes, USA) as described in [3] but using $10 \mu \mathrm{l}$ of aqueous extracts instead of $50 \mu \mathrm{l}$.

For confocal microscopy experiments and plastid isolation, fresh berries were collected at the green soft and color change stages during 2011.

Total protein was extracted from $6 \mathrm{~g}$ of skin powder plus 25\% (w/w) PVPP in $10 \mathrm{ml}$ lysis buffer $(0.2 \mathrm{M}$ sodium phosphate buffer, $\mathrm{pH}$ 7.5, 5 mM EDTA) containing protease inhibitors (Sigma, MO). Samples were incubated on ice for $10 \mathrm{~min}$ then centrifuged for $15 \mathrm{~min}$ at $15,000 \times g$ at $4^{\circ} \mathrm{C}$. The supernatant was clarified by precipitation with $30 \%$ ammonium sulfate and centrifugation at $20,000 \times g$ for $30 \mathrm{~min}$, washed to remove salts and concentrated on Amicon Ultra (Millipore). The protein concentration was determined using QuantIt (Invitrogen).

In vitro catalase activity was measured by spectrophotometry and mass spectrometry. In the first assay, catalase activity was measured in $250 \mu \mathrm{l}$ phosphate buffer $(\mathrm{pH} 7)$ at $25^{\circ} \mathrm{C}$ using $10 \mu \mathrm{g}$ of grape skin protein extract following [66]. The specific catalase activity was calculated using the $\mathrm{H}_{2} \mathrm{O}_{2}$ molar extinction coefficient at 240 $\mathrm{nm}\left(43.6 \mathrm{M}^{-1} \mathrm{~cm}^{-1}\right)$ and was expressed as moles of $\mathrm{H}_{2} \mathrm{O}_{2}$ consumed per min per mg total protein. In the second assay, catalase activity was measured in $180 \mathrm{ml} 50 \mathrm{mM}$ potassium phosphate buffer $(\mathrm{pH} 7)$ in the presence of 50 $\mathrm{mM} \mathrm{H} \mathrm{H}_{2} \mathrm{O}_{2}$ with a continuous nitrogen flux taking volatiles to the PTR-TOF-MS (Ionicon Analytik, Austria). The production of $\mathrm{O}_{2}$ was measured using the signal at $\mathrm{m} / z 32$ after the addition of $1 \mathrm{mg}$ grape skin protein extract. Preliminary calibration using bovine catalase (Sigma-Aldrich) showed that maximum $\mathrm{O}_{2}$ production $\left(\mathrm{O}_{2 \max }\right)$ was proportional to the enzyme concentration in the solution so $\mathrm{O}_{2 \max }$ was used to quantify catalase activity in the extracts.

Native gel and zymography catalase detection was done as described by [46]. SDS-PAGE was performed using precast $4-12 \%$ NuPAGE gels and $1 \times$ MOPS running buffer (Invitrogen). Proteins were transferred onto PVDF membranes (Millipore) using an XCell II Blot Module (Invitrogen) at $40 \mathrm{~V}$ for $1 \mathrm{~h}$. Membranes were blocked with 5\% BSA in TBST buffer for $1 \mathrm{~h}$ at room temperature and incubated overnight at $4^{\circ} \mathrm{C}$ with the primary antibody. Anti LOX-C plastidial lipoxygenase (AS07258, Agrisera) was used to detect VvLOXs. Anti catalase (AS09501, Agrisera) was used to detect VvCATs. Alkaline phosphatase-conjugated goat anti-rabbit AffiniPure (Jackson ImmunoResearch) was used as the secondary antibody; detection was performed using Alkaline phosphatase blue membrane substrate solution (Sigma-Aldrich).

\section{Preparation of chloroplasts}

Chloroplasts were prepared from $20 \mathrm{~g}$ skin tissue as described by [67]. Intact plastids were recovered using a 40-80\% Percoll gradient, washed with hypotonic lysis buffer and centrifuged for $10 \mathrm{~min}$ at $10,000 \times g$ to separate soluble and membrane-associated proteins. The pellet was divided into three parts, which were dissolved in $0.1 \%$ TritonX-100 or $1 \mathrm{M} \mathrm{NaCl}$ or control buffer. These three samples were centrifuged as above and the final soluble and membranous fractions were prepared for SDS-PAGE.

\section{Cloning and expression of recombinant PnLOXA}

The PnLOXA coding sequence (Vv06s0004g01510) without the plastid targeting sequence was amplified from Pinot Noir berry cDNA using Phusion DNA polymerase (Finnzymes) and the primers LOXfw5'BamHI 
(5'-GGATCCGTTGGCTACGTCCCTG-3') and LOXrev3'HindIII (5'-AAGCTTTCAAATGGAGATACTGTA TGGAA-3') and inserted into the pGEM-T vector for sequencing. PnLOXA was then transferred to the expression vector $\mathrm{pQE30}$ using the BamHI/HindIII restriction sites, thus adding an $\mathrm{N}$-terminal $\mathrm{His}_{6}$ tag. Escherichia coli M15 [pRep4] cells transformed with pQE30:PnLOXA were induced with $1 \mathrm{mM}$ IPTG and $2 \%$ ethanol for $16 \mathrm{~h}$ at $20^{\circ} \mathrm{C}$. A 1-L bacterial culture pellet was resuspended in $40 \mathrm{ml}$ of $50 \mathrm{mM}$ HEPES/NaOH buffer ( $\mathrm{pH}$ 7.5) containing $150 \mathrm{mM} \mathrm{NaCl}, 5 \mathrm{mM}$ DTT and protease inhibitors (Sigma). After sonication and lysozyme treatment $(0.2 \mathrm{mg} / \mathrm{ml})$, the cleared bacterial lysate was adjusted to $0.5 \mathrm{M} \mathrm{NaCl}$ and loaded onto a 5-ml HisTrap ${ }^{\text {tu }}$ FF crude Column (GE Healthcare, AKTA Purifier system) pre-equilibrated with binding buffer $(20 \mathrm{mM}$ HEPES- $\mathrm{NaOH} \mathrm{pH} 7.5,0.5 \mathrm{M}$ $\mathrm{NaCl})$. The column was washed with binding buffer and $50 \mathrm{mM}$ imidazole (Merck), and the $\mathrm{His}_{6}$-PnLOXA protein was eluted using $250 \mathrm{mM}$ imidazole. Protein yield was $2 \mathrm{mg}$ of pure protein per liter of bacterial culture. Recombinant PnLOXA activity was studied using $0.1 \mathrm{mM}$ $\alpha$-linolenic acid (Sigma) at $\mathrm{pH} 6.5$ and $25^{\circ} \mathrm{C}$.

\section{Transient expression in grapevine and tobacco leaves}

Three constructs were prepared for transient expression: two YFP fusion constructs for localization analysis, and the complete PnLOXA gene for functional analysis. The YFP coding sequence was subcloned from vector pAVA 554-p35S-YFP [68] into pSAT1-p35S-nVenus [69] using the restriction enzymes NcoI and BglII. The p35S-YFP cassette was then inserted into pGreen0029 using the EcoRV/NotI sites [70]. The 1-47 and 1-220 PnLOXA peptides were amplified using primers $5^{\prime}$ leaderBspHI (5' -TTGCTCATGATGTTCAAGACTCAGGTCCA-3'), 3 'leaderBspHI (5' -GCAGTCATGAGGCCAACCCTAAC ATTCCT-3') and 3'PLATBspHI (5'-CTTGATCATGAC TGGTGTTTCCAATGGTAAGT-3'). The PCR products were digested with BspHI and inserted into pGreen002935S-YFP, digested with NcoI. The pGreen[PnLOXA transitpeptide $\left.{ }_{1-47}-\mathrm{YFP}\right]$ and pGreen[PnLOXAtransitpeptidePLAT ${ }_{1-220}$-YFP] binary vectors were introduced into the Agrobacterium tumefaciens strain GV3101-pSoup [69,71] as described by [72].

The complete PnLOXA coding sequence was amplified from Pinot Noir cDNA using primers 5'leaderBspHI and LOXrev3'HindIII. The amplified product was introduced into vector pUC19 and sequenced. The $2450 \mathrm{bp}-$ NcoI/Xbal PnLOXA fragment from the pUC19-PnLOXA was cloned into the pGreen[PnLOXAtransitpeptide$\mathrm{PLAT}_{1-220}$-YFP] vector previously digested with NcoI and XbaI, obtaining the pGreen $[P n L O X A]$.

For PnLOXA transient expression in tobacco leaves, Agrobacterium transformed either with the pGreen empty vector or the pGreen[35S:PnLOXA] was inoculated into leaves of six tobacco plants, so that each tobacco plant was a biological replicate. For time-course expression analysis, leaves were collected from 4 to 12 days after infiltration and protein extracts analyzed by western blot. For galactolipid peroxidation analysis, western blot was used to quantify the PnLOXA expression in each biological replicate using Image J software and lipids were extracted as described below for HPLC-MS analysis.

\section{Lipid analysis}

Total lipids were extracted from frozen Pinot Noir berry skin samples according to [73]. We added $1 \mathrm{mM} 3,5$-ditert-butyl-4-hydroxytoluene (BHT) to the extraction buffer to prevent oxidation during sample preparation and $1 \mathrm{mM}$ triphenylphosphine (TPP) to reduce hydroperoxyl groups to hydroxyl groups, which are more stable and suitable for quantitative analysis. The extracts were dissolved in 90:10 methanol/chloroform and $5 \mu \mathrm{L}$ were injected into a Hewlett-Packard Model 1100 Series liquid chromatograph (Hewlett-Packard Development Company, CA) coupled to a photodiode array (PDA) detector (Agilent Technologies, Italy, Agilent 1100 Series) and to a Bruker Esquire-LC quadrupole ion-trap mass spectrometer (Bruker Optik $\mathrm{GmbH}$, Germany) equipped with atmospheric pressure electrospray ion source. Analysis was carried out at room temperature on an Agilent ZORBAX Eclipse XDB-C8 $150 \times 4.6 \mathrm{~mm}, 3.5 \mu \mathrm{m}$ column. The eluent $(0.8 \mathrm{~mL} / \mathrm{min})$ consisted of (A) methanol: water/12 $\mathrm{mM}$ ammonium acetate (70:30) and (B) methanol/12 $\mathrm{mM}$ ammonium acetate using a linear gradient: $35 \%-100 \%$ B in $40 \mathrm{~min}$, followed by isocratic B held for $10 \mathrm{~min}$. The details of the MS parameters have been described previously $[40,74]$. The regiochemical distribution of galactolipids was established as described by [40] using either short-wavelength UVDAD or ESI-MS detection. The relative percentage of peroxidation of MGDG 36:6 and DGDG 36:6 in all the samples was established by the ratio of the absolute ESI $(+)$ area of the extracted ion current (EIC) of each oxidized product with respect to the ESI $(+)$ area of the extracted ion current (EIC) of total (native and oxidized) MGDG and DGDG, respectively.

Galactolipids were purified by Si-60 flash chromatography and chloroform-methanol gradient elution. Near pure (TLC analysis) MGDGs and DGDGs were obtained in fractions 9 and 10, respectively. Fraction 10 was used as the DGDG substrate for in vitro enzymatic oxidation. Portions of fraction 9 and 10 were purified further by reverse phase HPLC (methanol/water gradient elution) to obtain pure (NMR analysis) MGDG 18:3/18:3 (1.5 mg) and DGDG 18:3/18:3 (1.4 mg).

MGDG 18:3/18:3 were hydrolyzed in methanol solution $(1 \mathrm{mM}, 200 \mu \mathrm{L})$ by treatment with an aqueous $\mathrm{KOH}$ solution $(500 \mathrm{mM}, 300 \mu \mathrm{L})$ for $1 \mathrm{~h}$ at room temperature. The basic solution was neutralized with $500 \mathrm{mM} \mathrm{HCl}$, and an 
organic extract was obtained by extracting three times with $400 \mu \mathrm{L}$ n-hexane. LC-MS analysis confirmed the presence in the hexane extracts of linolenic acid ( 90\%) and of its corresponding 13- hydroxy derivative (13-HOTrE). The peak corresponding to the latter was collected, evaporated and rinsed with $1 \mathrm{ml}$ methanol for chiral analysis. The CD spectrum of methanolic 13-HOTrE was recorded with a Jasco J710 spectropolarimeter.

${ }^{1} \mathrm{H}-\mathrm{NMR}$ spectra were obtained for MGDG 18:3/18:3 and DGDG 18:3/18:3 by dissolving each in $600 \mu \mathrm{L}$ tetradeuterated methanol (99.9\% CD3OD, Aldrich) and carrying out measurements at $298 \mathrm{~K}$ on a Bruker-Avance 400 $\mathrm{MHz}$ spectrometer with a $5-\mathrm{mm} \mathrm{BBI}$ probe set at a $90^{\circ}$ proton pulse length of $9.4 \mu$ s and a transmission power of $0 \mathrm{db}$. The chemical shift scale $(\delta)$ was calibrated on the residual proton signal of deuterated methanol at $\delta_{\mathrm{H}}$ $3.310 \mathrm{ppm}$.

\section{Confocal imaging}

ROS sensitive fluorescent dyes and YFP were imaged using a Leica SP5 confocal microscope (Leica, Germany). Dichlorofluorescein diacetate (DCFDA), hydroxyphenyl fluorescein (HPF) and singlet oxygen sensor green (SOSG, Molecular Probes) staining was carried out by preparing $100 \mu \mu \mathrm{m}$ berry sections on a microtome, and incubating them for $2 \mathrm{~h}$ at room temperature in the dark with $30 \mu \mathrm{M}$ DCFDA, $30 \mu \mathrm{M}$ SOSG or $10 \mu \mathrm{m}$ HPF dissolved in $50 \mathrm{mM}$ sodium phosphate buffer ( $\mathrm{pH}$ 7.5). The excitation wavelength was $488 \mathrm{~nm}$ and the emission wavelengths were 500-535 nm, 500-540 nm, 505-535 nm and 675-725 nm for DCFDA, SOSG, HPF and chlorophyll, respectively.

For PnLOXA localization study, leaf pieces from the agroinfiltrated areas collected at 6 days after infiltration were mounted on slides. YFP detection was carried out using excitation and emission wavelengths of $488 \mathrm{~nm}$ and 515/530 $\mathrm{nm}$, respectively.

Confocal images were processed using ImageJ software.

\section{Quantitative RT-PCR}

Total RNA was extracted from grapevine tissues using the Spectrum Total Plant RNA kit (Sigma) and quantified using Nanodrop 8000 (Thermo Scientific). Integrity was checked by capillary electrophoresis using Bioanalyzer 2100 (Agilent). First strand cDNA was synthesized from $2 \mu \mathrm{g}$ RNA using the SuperScript VILO cDNA Synthesis Kit (Invitrogen) according to the manufacturer's instructions, with the primers indicated in Additional file 7. The cDNAs were mixed with Fast SYBR Green Master Mix (Applied Biosystems) and amplified on a ViiA 7 Real Time PCR System (Applied Biosystems) using an initial heating step of $95^{\circ} \mathrm{C}$ for $20 \mathrm{sec}$, followed by 40 cycles of $95^{\circ} \mathrm{C}$ for $1 \mathrm{sec}$ and $60^{\circ} \mathrm{C}$ for $20 \mathrm{sec}$. Raw fluorescence data were extracted using Viia 7 Software v1.0. Ct and reaction efficiency were calculated using LinRegPCR software [75].
Relative expression was calculated according to [76] by centering expression values for each gene on the mean value. Three reference genes out of five (ubiquitin, SAND and GAPDH) were selected by geNorm and used for normalization [77].

\section{Additional files}

Additional file 1: $\mathrm{H}_{2} \mathrm{O}_{2}$ content quantification and lipid peroxidation analysis of Pinot noir berry skin extracts during season 2008.

Additional file 2: Mass spectrometry analyses results for PnLOXA identification.

Additional file 3: Updated description of the Vitis vinifera LOX gene family; heatmap of the LOX gene family expression in the $V$. vinifera cv Corvina atlas and transcriptional profiles of the 5 LOX genes expressed in Corvinia berries.

Additional file 4: PnLOXA localization demonstrated by transient expression of YFP fusion constructs in tobacco leaves.

Additional file 5: Western analysis of tobacco leaves transiently overexpressing PnLOXA.

Additional file 6: Phylogenetic analysis of LOX sequences from Vitis vinifera, Solanum lycopersicum and Arabidopsis thaliana.

Additional file 7: List of primer sequences used in RT-PCR analysis.

\section{Abbreviations}

ROS: Reactive oxygen species; MGDG: Monogalactosyl diacylglycerol; DGDG: Digalactosyl diacylglycerol; $\mathrm{H}_{2} \mathrm{O}_{2}$ : Hydrogen peroxide; ${ }^{1} \mathrm{O}_{2}$ : Singlet oxygen; 13HOTrE: (9Z,11E,15Z)-13-(S)-hydroxyoctadecatrienoic acid.

\section{Competing interests}

The authors declare that they have no conflict of interest.

\section{Authors' contribution}

SP substantially contributed to conception, performed enzymatic assays, statistical analysis and manuscript drafting. DB carried out ROS visualization at confocal microscope and helped in biochemical assays. GG performed all lipid identification and analyses. AM identified the lipoxygenase protein by mass spectrometry. CR and MZ carried out the tobacco and grapevine transient expression and localization analyses. FB carried out catalase activity assay by PTR-MS. CM substantially contributed to the study conception and design and manuscript drafting. All authors read and approved the final manuscript.

\section{Acknowledgements}

The authors wish to thank Adriano Sterni for expert technical assistance relating to HPLC-MS analysis, Roberto Larcher and Mario Malacarne for must analyses, Omar Rota-Stabelli for the phylogenetic analysis and Ron Wehrens for help in statistical analyses using $\mathrm{R}$.

\section{Funding}

This work was supported by the Autonomous Province of Trento and Veneto Region Innovation Grant.

\section{Author details}

${ }^{1}$ Research and Innovation Centre, Fondazione Edmund Mach, via E. Mach 1, 38010 San Michele a/Adige, TN, Italy. ${ }^{2}$ Department of Physics, Bioorganic Chemistry Lab, University of Trento, Via Sommarive 14, 38123 Trento, Povo, Italy. ${ }^{3}$ CNR, Istituto di Biofisica Trento, Via alla Cascata 56/C, 38123 Trento, Povo, Italy. ${ }^{4}$ Department of Biology, University of Padova, Via U. Bassi 58/b, 35131 Padova, Italy.

Received: 22 October 2013 Accepted: 20 March 2014

Published: 2 April 2014 


\section{References}

1. Terrier N, Glissant D, Grimplet J, Barrieu F, Abbal P, Couture C, Ageorges A, Atanassova R, Léon C, Renaudin J-P, Dédaldéchamp F, Romieu C, Delrot $S$, Hamdi S: Isogene specific oligo arrays reveal multifaceted changes in gene expression during grape berry (Vitis vinifera L.) development. Planta 2005, 222:832-847.

2. Deluc LG, Grimplet J, Wheatley MD, Tillett RL, Quilici DR, Osborne C, Schooley DA, Schlauch KA, Cushman JC, Cramer GR: Transcriptomic and metabolite analyses of Cabernet Sauvignon grape berry development. BMC Genomics 2007, 8:429.

3. Pilati S, Perazzolli M, Malossini A, Cestaro A, Demattè L, Fontana P, Dal Ri A, Viola R, Velasco R, Moser C: Genome-wide transcriptional analysis of grapevine berry ripening reveals a set of genes similarly modulated during three seasons and the occurrence of an oxidative burst at vèraison. BMC Genomics 2007, 8:428.

4. Lund S, Peng F, Nayar T, Reid K, Schlosser J: Gene expression analyses in individual grape (Vitis vinifera L.) berries during ripening initiation reveal that pigmentation intensity is a valid indicator of developmental staging within the cluster. Plant Mol Biol 2008, 68:301-315.

5. Zenoni S, Ferrarini A, Giacomelli E, Xumerle L, Fasoli M, Malerba G, Bellin D, Pezzotti M, Delledonne M: Characterization of transcriptional complexity during berry development in Vitis vinifera using RNA-Seq1 [W]. Plant Physiol 2010, 152:1787-1795.

6. Fortes AM, Agudelo-Romero P, Silva MS, Ali K, Sousa L, Maltese F, Choi YH, Grimplet J, Martinez- Zapater JM, Verpoorte R, Pais MS: Transcript and metabolite analysis in Trincadeira cultivar reveals novel information regarding the dynamics of grape ripening. BMC Plant Biol 2011, 11:149.

7. Lijavetzky D, Carbonell-Bejerano P, Grimplet J, Bravo G, Flores P, Fenoll J, Hellín P, Oliveros JC, Martínez-Zapater JM: Berry flesh and skin ripening features in vitis vinifera as assessed by transcriptional profiling. PLoS One 2012, 7:e3954

8. Böttcher C, Boss PK, Davies C: Acyl substrate preferences of an IAA-amido synthetase account for variations in grape (Vitis vinifera L.) berry ripening caused by different auxinic compounds indicating the importance of auxin conjugation in plant development. J Exp Bot 2011, 62:4267-4280.

9. Gambetta GA, Matthews MA, Shaghasi TH, McElrone AJ, Castellarin SD: Sugar and abscisic acid signaling orthologs are activated at the onset of ripening in grape. Planta 2010, 232:219-234.

10. Giribaldi M, Gény L, Delrot $\mathrm{S}$, Schubert A: Proteomic analysis of the effects of $A B A$ treatments on ripening Vitis vinifera berries. J Exp Bot 2010, 61:2447-2458.

11. Symons GM, Davies C, Shavrukov Y, Dry IB, Reid JB, Thomas MR: Grapes on steroids. Brassinosteroids are involved in grape berry ripening. Plant Physiol 2006, 140:150-158

12. Chervin C, Tira-umphon A, Terrier N, Zouine M, Severac D, Roustan J-P: Stimulation of the grape berry expansion by ethylene and effects on related gene transcripts, over the ripening phase. Physiol Plant 2008, 134:534-546.

13. Sun L, Zhang M, Ren J, Qi J, Zhang G, Leng P: Reciprocity between abscisic acid and ethylene at the onset of berry ripening and after harvest. BMC Plant Biol 2010, 10:257.

14. Castellarin SD, Gambetta GA, Wada H, Shackel KA, Matthews MA: Fruit ripening in Vitis vinifera: spatiotemporal relationships among turgor, sugar accumulation, and anthocyanin biosynthesis. J Exp Bot 2011, 62:4345-4354.

15. Yu X-C, Li M-J, Gao G-F, Feng H-Z, Geng X-Q, Peng C-C, Zhu S-Y, Wang X-J, Shen Y-Y, Zhang D-P: Abscisic acid stimulates a calcium-dependent protein Kinase in grape berry. Plant Physiol 2006, 140:558-579.

16. Giribaldi M, Perugini I, Sauvage F-X, Schubert A: Analysis of protein changes during grape berry ripening by 2-DE and MALDI-TOF. Proteomics 2007, 7:3154-3170.

17. Negri AS, Prinsi B, Rossoni M, Failla O, Scienza A, Cocucci M, Espen L: Proteome changes in the skin of the grape cultivar Barbera among different stages of ripening. BMC Genomics 2008, 9:378.

18. Triantaphylidès $C$, Havaux M: Singlet oxygen in plants: production, detoxification and signaling. Trends Plant Sci 2009, 14:219-228.

19. Foreman J, Demidchik V, Bothwell JHF, Mylona P, Miedema H, Torres MA, Linstead P, Costa S, Brownlee C, Jones JDG, Davies JM, Dolan L: Reactive oxygen species produced by NADPH oxidase regulate plant cell growth. Nature 2003, 422:442-446.
20. Torres MA, Dangl JL: Functions of the respiratory burst oxidase in biotic interactions, abiotic stress and development. Curr Opin Plant Biol 2005, 8:397-403.

21. D'Autréaux B, Toledano MB: ROS as signalling molecules: mechanisms that generate specificity in ROS homeostasis. Nat Rev Mol Cell Biol 2007, 8:813-824.

22. Mullineaux PM, Baker NR: Oxidative stress: antagonistic signaling for acclimation or cell death? Plant Physiol 2010, 154:521-525.

23. Gadjev I, Vanderauwera S, Gechev TS, Laloi C, Minkov IN, Shulaev V, Apel K, Inzé $D$, Mittler R, Van Breusegem F: Transcriptomic footprints disclose specificity of reactive oxygen species signaling in arabidopsis. Plant Physiol 2006, 141:436-445.

24. Petrov VD, Van Breusegem F: Hydrogen peroxide-a central hub for information flow in plant cells. AoB Plants 2012, 2012:pls014.

25. Ophir R, Pang X, Halaly T, Venkateswari J, Lavee S, Galbraith D, Or E: Gene-expression profiling of grape bud response to two alternative dormancy-release stimuli expose possible links between impaired mitochondrial activity, hypoxia, ethylene-ABA interplay and cell enlargement. Plant Mol Biol 2009, 71:403-423.

26. Oracz K, El-Maarouf-Bouteau H, Kranner I, Bogatek R, Corbineau F, Bailly C: The mechanisms involved in seed dormancy alleviation by hydrogen cyanide unravel the role of reactive oxygen species as key factors of cellular signaling during germination. Plant Physiol 2009, 150:494-505.

27. Jimenez A, Creissen G, Kular B, Firmin J, Robinson S, Verhoeyen M, Mullineaux P: Changes in oxidative processes and components of the antioxidant system during tomato fruit ripening. Planta 2002, 214:751-758.

28. Ye Z, Rodriguez R, Tran A, Hoang H, De los Santos D, Brown S, Vellanoweth RL: The developmental transition to flowering represses ascorbate peroxidase activity and induces enzymatic lipid peroxidation in leaf tissue in Arabidopsis thaliana. Plant Sci 2000, 158:115-127.

29. Triantaphylidès C, Krischke M, Hoeberichts FA, Ksas B, Gresser G, Havaux M, Van Breusegem F, Mueller MJ: Singlet oxygen is the major reactive oxygen species involved in photooxidative damage to plants. Plant Physiol 2008, 148:960-968.

30. Kim C, Meskauskiene R, Apel K, Laloi C: No single way to understand singlet oxygen signalling in plants. EMBO Reports 2008, 9:435-439.

31. Alboresi A, Dall'Osto L, Aprile A, Carillo P, Roncaglia E, Cattivelli L, Bassi R: Reactive oxygen species and transcript analysis upon excess light treatment in wild-type Arabidopsis thaliana vs a photosensitive mutant lacking zeaxanthin and lutein. BMC Plant Biol 2011, 11:62.

32. Ramel F, Birtic $S$, Ginies $C$, Soubigou-Taconnat L, Triantaphylidès $C$, Havaux M: Carotenoid oxidation products are stress signals that mediate gene responses to singlet oxygen in plants. Proc Natl Acad Sci U S A 2012, 109:5535-5540.

33. Montillet J-L, Cacas J-L, Garnier L, Montané M-H, Douki T, Bessoule J-J, Polkowska-Kowalczyk L, Maciejewska U, Agnel J-P, Vial A, Triantaphylidès C: The upstream oxylipin profile of Arabidopsis thaliana: a tool to scan for oxidative stresses. Plant J 2004, 40:439-451.

34. Mosblech A, Feussner I, Heilmann I: Oxylipins: structurally diverse metabolites from fatty acid oxidation. Plant Physiol Biochem 2009, 47:511-517

35. Farmer EE, Mueller MJ: ROS-mediated lipid peroxidation and RESactivated signaling. Annu Rev Plant Biol 2013, 64:429-450.

36. Kalua CM, Boss PK: Evolution of volatile compounds during the development of cabernet sauvignon grapes (Vitis vinifera L.). J Agric Food Chem 2009, 57:3818-3830.

37. Vellosillo T, Martínez M, López MA, Vicente J, Cascón T, Dolan L, Hamberg M, Castresana C: Oxylipins produced by the 9-lipoxygenase pathway in arabidopsis regulate lateral root development and defense responses through a specific signaling cascade. Plant Cell 2007, 19:831-846

38. López MA, Vicente J, Kulasekaran S, Vellosillo T, Martínez M, Irigoyen ML, Cascón T, Bannenberg G, Hamberg M, Castresana C: Antagonistic role of 9-lipoxygenase-derived oxylipins and ethylene in the control of oxidative stress, lipid peroxidation and plant defence. Plant J 2011, 67:447-458.

39. Andreou A, Feussner I: Lipoxygenases-structure and reaction mechanism. Phytochemistry 2009, 70:1504-1510.

40. Guella G, Frassanito R, Mancini I: A new solution for an old problem: the regiochemical distribution of the acyl chains in galactolipids can be 
established by electrospray ionization tandem mass spectrometry. Rapid Commun Mass Spectrom 2003, 17:1982-1994.

41. Podolyan A, White J, Jordan B, Winefield C: Identification of the lipoxygenase gene family from Vitis vinifera and biochemical characterisation of two 13-lipoxygenases expressed in grape berries of Sauvignon Blanc. Funct Plant Biol 2010, 37:767-784.

42. Fasoli M, Dal Santo S, Zenoni S, Tornielli GB, Farina L, Zamboni A, Porceddu A Venturini L, Bicego M, Murino V, Ferrarini A, Delledonne M, Pezzotti M: The grapevine expression atlas reveals a deep transcriptome shift driving the entire plant into a maturation program. Plant Cell 2012, 24:3489-3505.

43. Farmaki T, Sanmartín M, Jiménez $P$, Paneque M, Sanz C, Vancanneyt G, León J, Sánchez-Serrano JJ: Differential distribution of the lipoxygenase pathway enzymes within potato chloroplasts. J Exp Bot 2007, 58:555-568.

44. Chen G, Hackett R, Walker D, Taylor A, Lin Z, Grierson D: Identification of a specific isoform of tomato lipoxygenase (TomloxC) involved in the generation of fatty acid-derived flavor compounds. Plant Physiol 2004, 136:2641-2651.

45. Queval G, Hager J, Gakière B, Noctor G: Why are literature data for $\mathrm{H} 2 \mathrm{O} 2$ contents so variable? A discussion of potential difficulties in the quantitative assay of leaf extracts. J Exp Bot 2008, 59:135-146.

46. Zimmermann P, Heinlein C, Orendi G, Zentgraf U: Senescence-specific regulation of catalases in Arabidopsis thaliana (L.) Heynh. Plant Cell Environ 2005, 29:1049-1060.

47. Terrier N, Romieu C: Grape berry acidity. In Molecular Biology \& Biotechnology of the Grapevine. Edited by Roubelakis-Angelakis KA. Springer: Kluwer Academic Publishers; 2001:35-37.

48. Pérez FJ, Burgos B: Alterations in the pattern of peroxidase isoenzymes and transient increases in its activity and in $\mathrm{H} 2 \mathrm{O} 2$ levels take place during the dormancy cycle of grapevine buds: the effect of hydrogen cyanamide. Plant Growth Regul 2004, 43:213-220.

49. Vergara R, Parada F, Rubio S, Pérez FJ: Hypoxia induces $\mathrm{H} 2 \mathrm{O} 2$ production and activates antioxidant defence system in grapevine buds through mediation of $\mathrm{H} 2 \mathrm{O} 2$ and ethylene. J Exp Bot 2012, 63:4123-4131.

50. Or E, Vilozny I, Fennell A, Eyal Y, Ogrodovitch A: Dormancy in grape buds: isolation and characterization of catalase CDNA and analysis of its expression following chemical induction of bud dormancy release. Plant Sci 2002, 162:121-130.

51. Pérez FJ, Lira W: Possible role of catalase in post-dormancy bud break in grapevines. J Plant Physio/ 2005, 162:301-308.

52. Krieger-Liszkay A: Singlet oxygen production in photosynthesis. J Exp Bot 2005, 56:337-346.

53. Negri AS, Robotti E, Prinsi B, Espen L, Marengo E: Proteins involved in biotic and abiotic stress responses as the most significant biomarkers in the ripening of Pinot Noir skins. Funct Integr Genom 2011, 11:341-355.

54. Marchive C, Leon C, Kappel C, Coutos-Thevenot P, Corio-Costet M-F, Delrot S, Lauvergeat $\mathrm{V}$ : Over-expression of VvWRKY1 in grapevines induces expression of jasmonic acid pathway-related genes and confers higher tolerance to the downy mildew. PLoS One 2013, 8:e54185.

55. Zoeller M, Stingl N, Krischke M, Fekete A, Waller F, Berger S, Mueller MJ: Lipid profiling of the Arabidopsis hypersensitive response reveals specific lipid peroxidation and fragmentation processes: biogenesis of pimelic and azelaic acid. Plant Physiol 2012, 160:365-378.

56. Schaller S, Latowski D, Jemioła-Rzemińska M, Wilhelm C, Strzałka K, Goss R: The main thylakoid membrane lipid monogalactosyldiacylglycerol (MGDG) promotes the de-epoxidation of violaxanthin associated with the light-harvesting complex of photosystem II (LHCII). Biochim Biophys Acta 2010, 1797:414-424.

57. Wu W, Ping W, Wu H, Li M, Gu D, Xu Y: Monogalactosyldiacylglycerol deficiency in tobacco inhibits the cytochrome b6f-mediated intersystem electron transport process and affects the photostability of the photosystem II apparatus. Biochim Biophys Acta 2013, 1987:709-722.

58. Fischer BB, Ledford HK, Wakao S, Huang SG, Casero D, Pellegrini M, Merchant SS, Koller A, Eggen RIL, Niyogi KK: SINGLET OXYGEN RESISTANT 1 links reactive electrophile signaling to singlet oxygen acclimation in Chlamydomonas Reinhardtii. PNAS 2012, 109:E1302-E1311.

59. Griffiths A, Barry C, Alpuche-Solis AG, Grierson D: Ethylene and developmental signals regulate expression of lipoxygenase genes during tomato fruit ripening. J Exp Bot 1999, 50:793-798.

60. Kovács K, Fray RG, Tikunov Y, Graham N, Bradley G, Seymour GB, Bovy AG, Grierson D: Effect of tomato pleiotropic ripening mutations on flavour volatile biosynthesis. Phytochemistry 2009, 70:1003-1008.
61. Tieman D, Bliss P, Mclntyre LM, Blandon-Ubeda A, Bies D, Odabasi AZ, Rodríguez GR, Van der Knaap E, Taylor MG, Goulet C, Mageroy MH, Snyder DJ, Colquhoun T, Moskowitz H, Clark DG, Sims C, Bartoshuk L, Klee HJ: The chemical interactions underlying tomato flavor preferences. Curr Biol 2012, 22:1035-1039.

62. Qin G, Wang Y, Cao B, Wang W, Tian S: Unraveling the regulatory network of the MADS box transcription factor RIN in fruit ripening. Plant J 2011, 70:243-255.

63. Mueller S, Hilbert B, Dueckershoff K, Roitsch T, Krischke M, Mueller MJ, Berger S: General detoxification and stress responses are mediated by oxidized lipids through TGA transcription factors in Arabidopsis. Plant Cell 2008, 20:768-785.

64. Conrad M, Sandin Å, Förster H, Seiler A, Frijhoff J, Dagnell M, Bornkamm GW, Rådmark O, Van Huijsduijnen RH, Aspenström P, Böhmer F, Östman A: 12/15-lipoxygenase-derived lipid peroxides control receptor tyrosine kinase signaling through oxidation of protein tyrosine phosphatases. Proc Natl Acad Sci U S A 2010, 107:15774-15779.

65. Cheng GW, Breen PJ: Activity of phenylalanine ammonia-lyase (PAL) and concentrations of anthocyanins and phenolics in developing strawberry fruit. J Amer Soc Hort Sci 1991, 16:865-869.

66. Aebi H: Catalase in vitro. Meth Enzymol 1984, 105:121-126.

67. Gegengeimer P: Preparation of Extracts from Plants. In Guide to Protein Purification, Volume 182. Edited by Deutscher MP. Academic Press; 1990:174-193 [Abelson J, Simon M, Verdine G, Pyle A (Series Editors): Methods in Enzymology].

68. Von Arnim A, Deng X-W, Stacey M: Cloning vectors for the expression of green fluorescent protein fusion proteins in transgenic plants. Gene 1998, 221:35-43.

69. Lee L-Y, Fang M-J, Kuang L-Y, Gelvin SB: Vectors for multi-color bimolecular fluorescence complementation to investigate protein-protein interactions in living plant cells. Plant Methods 2008, 4:24.

70. Hellens R, Mullineaux P, Klee H: Technical Focus: A guide to Agrobacterium binary Ti vectors. Trends Plant Sci 2000, 5:446-451.

71. Van Larebeke N, Engler G, Holsters M, Van den Elsacker S, Zaenen I, Schilperoort RA, Schell J: Large plasmid in Agrobacterium tumefaciens essential for crown gall-inducing ability. Nature 1974, 252:169-170.

72. Zottini M, Barizza E, Costa A, Formentin E, Ruberti C, Carimi F, Lo Schiavo F: Agroinfiltration of grapevine leaves for fast transient assays of gene expression and for long-term production of stable transformed cells. Plant Cell Rep 2008, 27:845-853.

73. Bligh $E G$, Dyer WJ: A rapid method of total lipid extraction and purification. Can J Biochem Physiol 1959, 37:911-917.

74. Frassanito R, Cantonati M, Tardio M, Mancini I, Guella G: On-line identification of secondary metabolites in freshwater microalgae and cyanobacteria by combined liquid chromatography-photodiode array detection-mass spectrometric techniques. J Chromatogr A 2005, 1082:33-42

75. Ruijter JM, Ramakers C, Hoogaars WMH, Karlen Y, Bakker O, Van den Hoff MJB, Moorman AFM: Amplification efficiency: linking baseline and bias in the analysis of quantitative PCR data. Nucleic Acids Res 2009, 37:e45.

76. Pfaffl MW: A new mathematical model for relative quantification in real-time RT-PCR. Nucleic Acids Res 2001, 29:e45.

77. Vandesompele J, De Preter K, Pattyn F, Poppe B, Van Roy N, De Paepe A, Speleman F: Accurate normalization of real-time quantitative RT-PCR data by geometric averaging of multiple internal control genes. Genome Biol 2002, 3:research0034.1-research0034.11.

doi:10.1186/1471-2229-14-87

Cite this article as: Pilati et al:: The onset of grapevine berry ripening is characterized by ROS accumulation and lipoxygenase-mediated membrane peroxidation in the skin. BMC Plant Biology 2014 14:87. 